\title{
Toward large scale modeling of carbon nanotube systems with the mesoscopic distinct element method
}

\author{
I. A. Ostanin ${ }^{1, \dagger}$, P. Zhilyaev ${ }^{2}$, V. Petrov², T. Dumitrica ${ }^{3}$, S. Eibl ${ }^{4}$, U. Ruede ${ }^{4,5}$, V. A. Kuzkin ${ }^{6,7}$ \\ †i.ostanin@skoltech.ru \\ ${ }^{1}$ Center for Computational and Data-Intensive Science and Engineering, Skolkovo Institute of Science and Technology, \\ 3 Nobel St., Moscow, 121205, Russia \\ ${ }^{2}$ Center for Design, Manufacturing and Materials, Skolkovo Institute of Science and Technology, \\ 3 Nobel St., Moscow, 121205, Russia \\ ${ }^{3}$ Department of Mechanical Engineering, University of Minnesota, 111 Church Street SE Minneapolis, MN, 55455, USA \\ ${ }^{4}$ Department of Computer Science, Friedrich-Alexander University Erlangen-Nuremberg, Cauerstr.11, Erlangen, 91052, Germany \\ ${ }^{5}$ Centre Européen de Recherche et de Formation Avancée en Calcul Scientifique (CERFACS), \\ 42 Avenue Gaspard Coriolis, 31057 Toulouse Cedex 1, France \\ ${ }^{6}$ Peter the Great St. Petersburg Polytechnic University, Polytechnicheskaya str. 29, St. Petersburg, 195251, Russia \\ ${ }^{7}$ Institute for Problems in Mechanical Engineering RAS, Bolshoy pr. V. O. 61, St. Petersburg, 199178, Russia
}

\begin{abstract}
A new scalable and efficient implementation of the mesoscopic distinct element method for massively parallel numerical simulations of carbon nanotube systems is introduced. Carbon nanotubes are represented as chains of rigid bodies, linked by elastic bonds and dispersive van der Waals (vdW) forces. The enhanced vector model formalism of the elastic bond between rigid bodies, developed recently, is employed here to capture the elastic deformation of nanotubes. Dispersive interactions between the neighboring nanotubes are described with the coarse-grained vdW potential. Time integration is performed using a velocity Verlet integration scheme with tunable damping in order to describe the energy dissipation to the implicit degrees of freedom. Due to the scalable message passing interface (MPI) parallelization, enabled by rigid particle dynamics module (PE) of the waLBerla multiphysics framework, our method is capable of modeling large assemblies of carbon nanotubes. This advance enables us to move closer to the length and time scales required to extract representative mechanics of carbon nanotube materials. The promising scalability of the new implementation is probed in two examples of self-assembly of ultrathin carbon nanotube films and carbon nanotube buckypapers, where formation of hierarchical networks of carbon nanotube bundles, storing both elastic and vdW adhesion energies is observed. The relaxation of one cubic micrometer of buckypaper illustrates the code scalability.
\end{abstract}

Keywords: carbon nanotubes, distinct element method, parallel computing, enhanced vector model.

УДК: 51-72, 519.6

\section{Масштабируемое моделирование систем из углеродных нанотрубок при помощи мезомасштабного метода \\ дискретного элемента}

\author{
Останин И. А. ${ }^{1, \dagger}$ Ж Жиляев П. А. ${ }^{2}$, Петров В. А. ${ }^{2}$, Dumitrica T. ${ }^{3}$, Eibl S. \\ Ruede U., ${ }^{4,5}$, Кузькин В. А. ${ }^{6,7}$

\footnotetext{
${ }^{1}$ Центр по научным и инженерным вычислительным технологиям для задач с большими массивами данных, Сколковский институт науки и технологии, ул. Нобеля, 3, Москва, 121205, Россия ${ }^{2}$ Центр по проектированию, производственным технологиям и материалам, Сколковский институт науки и технологии, ул. Нобеля, 3, Москва, 121205, Россия ${ }^{3}$ Department of Mechanical Engineering, University of Minnesota, 111 Church Street SE Minneapolis, MN, 55455, USA
} 
${ }^{4}$ Department of Computer Science, Friedrich-Alexander University Erlangen-Nuremberg, Cauerstr.11, Erlangen, 91052, Germany ${ }^{5}$ Centre Européen de Recherche et de Formation Avancée en Calcul Scientifique (CERFACS),

42 Avenue Gaspard Coriolis, 31057 Toulouse Cedex 1, France

${ }^{6}$ Санкт-Петербургский политехнический университет Петра Великого, ул. Политехническая, 29, Санкт-Петербург, 195251, Россия

${ }^{7}$ Институт проблем машиноведения РАН, Большой проезд В.О. 61, Санкт-Петербург, 199178, Россия

В работе предлагается новая, масштабируемая и эффективная реализация мезомасштабного метода дискретного элемента для массивно-параллельного моделирования систем из углеродных нанотрубок. Углеродные нанотрубки представлены в виде цепочек взаимодействующих твердых тел, связанных упругими связями и взаимодействующих через дисперсионные силы Ван дер Ваальса. Для описания упругих деформаций углеродных нанотрубок применяется недавно разработанная усовершенствованная векторная модель упругой связи. Дисперсионные взаимодействия между соседними нанотрубками описываются при помощи огрубленного потенциала Ван дер Ваальса. Интегрирование по времени осуществляется при помощи алгоритма Верле, с небольшим демпфированием для описания перехода энергии в микроскопические степени свободы. Благодаря высокомасштабируемой МPI параллелизации, обеспечиваемой средой waLBerla/PE для моделирования движения системы твердых тел, наш метод способен моделировать весьма большие массивы углеродных нанотрубок. В результате удается приблизиться к пространственным и временным масштабам, необходимым для моделирования материалов из углеродных нанотрубок. Масштабируемость предлагаемого подхода продемонстрирована на примерах самосборки сверхтонкой пленки и бумаги из углеродных нанотрубок, в которых наблюдалось формирование иерархических сетей нанотрубок, запасающих энергию упругой деформации и ван-дер-ваальсова прилипания. В частности, удалось провести моделирование релаксации одного кубического микрометра бумаги из углеродных нанотрубок.

Ключевые слова: углеродные нанотрубки, метод дискретного элемента, параллельные вычисления, расширенная векторная модель.

\section{Introduction}

Carbon nanotubes (CNTs) [1] and carbon nanotube materials show great promise in a number of industrial applications, including fine coatings, flexible electronics, ultrastrong ropes and reinforcement fibers [2-4]. However, intricate hierarchical structures of such materials, their discontinuous behavior with non-trivial tribology, as well as the prohibitively large sizes of representative volume elements prevented straightforward theoretical prediction of the mechanical, electrical and thermal properties of large CNT assembles.

Understanding of the mesoscale behavior of such materials can be improved via numerical simulations. While microscopic simulation techniques, such as tight-binding and molecular dynamics methods, were proved to be efficient numerical tools for modeling individual nanotubes and their interactions [5-8], the scalability of such techniques is insufficient for modeling large numbers of long CNTs, necessary for studying the mechanics of the representatively large specimens of CNT materials. In order to address this problem, a number of mesoscale models were suggested. The simplest one, bead-spring model [9-11], utilizes the idea of coarse-grained molecular dynamics, initially proposed for modeling polymer chains. Within this modeling concept, a chain of point masses - beads, represents a CNT interacting via classic potentials, representing either coarse-grained covalent bonding within a CNT, or dispersive interactions between the neighboring CNTs. Such a model, in spite of its obvious merits, has few fundamental limitations in a context of CNT modeling. One of them is the absence of torsional degrees of freedom leading to unrealistic behaviors of CNT assemblies under certain loadings. In order to address this problem, an essentially different coarse-graining concept was suggested [12 - 16] basing on a representation of a thin fiber (CNT) as a chain of rigid bodies, rather than point masses. Such a model allows not only bending of individual fibers, but their torsion as well. Such an extension enabled studies of twisted ropes and bundles of CNTs [16]. This modeling technique, known as mesoscopic distinct element method (MDEM), established itself in the field as one of the most efficient mesoscopic modeling tools, both computationally inexpensive and physically justified. Until now, the remaining obstacle on the route towards large-scale application of MDEM was the absence of its scalable, parallel and freely available implementation, since it was implemented only within a commercial package PFC3D [17], limiting the simulations with few hundred thousands rigid bodies and few millions of van der Waals (vdW) contacts. In this work, we demonstrate a fully functional, massively parallel implementation of MDEM for modeling CNT systems, utilizing one of the most advanced rigid body dynamic computational engines - rigid particle dynamics module of the waLBerla multiphysics framework [18].

In order to ensure the stability of large-scale simulations of CNT assemblies, we use the recently developed enhanced vector model (EVM) [19, 20] for the description of the bonds between rigid CNT segments. Unlike previously employed parallel bonds [21], EVM provides precise energy conservation in zero-damping simulations, and can be easily generalized to capture nonlinear effects and bond fracture.

Enriched with the scalable parallelization and EVM description of CNT elasticity, MDEM promises to become the leading technique for modeling mesoscale mechanics of CNT materials. 


\section{Method}

In this section, we describe the features of the new implementation of MDEM. The core difference with the previous implementation [13-15] is the usage of scalable dynamic engine [18] and energy conserving elastic bonds $[19,20]$. For the purpose of completeness, we provide a brief yet complete description of our model.

MDEM is a numerical technique for computing the damped dynamics of a collection of interacting classical particles. These particles are rigid bodies of arbitrary shape. Although a number of primitive shapes is readily available in the framework, here we utilize only rigid spheres with the radius $r$, and uniformly distributed mass $m$. The equations of motion of a system of rigid particles are solved using an explicit velocity Verlet finite difference algorithm. The forces and moments on each interacting particle are derived from contact models prescribed in advance. In the following, we give a concise overview of these contact models and provide their parameterization for a $(10,10) \mathrm{CNT}$ (lattice numbers define the radius of $\mathrm{CNT}$ ). The representation of a CNT as a chain of rigid segments relies on the following coarsegraining procedure. An undeformed CNT is homogenized into a cylindrical shell with finite thickness, which is then partitioned into identical mass representative elements (REs) of a CNT, each of finite length $T$ (Fig. 1).

Each spherical particle represents a mass RE. In this work we chose to partition a $(10,10) \mathrm{CNT}$ with diameter $2 r=13.56 \AA$ into mass REs with $T=2 r_{C N T}$. This way, each mass RE contains about 220 carbon atoms. Parameters $m$ and $I$ are chosen to match mass and moment of inertia of a RE taken with respect to the CNT axis. It follows that the spherical particle has a radius $r_{I}=\sqrt{2.5} r_{C N T}$. The spherical particles are equispaced at a distance $T$ apart along CNT axis.

The segments of neighboring CNTs interact via a vdW contact model. The design of the vdW contact model is based on the microscopic integration of vdW interactions of individual atoms in the assumption of valid superposition of vdW interactions. In this work, we utilize the simplest model of vdW interactions - isotropic coarse-grained vdW potential, obtained by microscopic integration of LennardJones potential for carbon, in the assumption of uniform distribution of carbon atoms over cylindrical surfaces of carbon nanotubes [12]. An isotropic vdW potential $U$ and the corresponding force $\mathbf{F}$ are given by

$$
\begin{aligned}
& U_{i j}\left(D_{i j}\right)=\left\{\begin{array}{c}
4 \varepsilon\left(\frac{A}{D_{i j}{ }^{\alpha}}-\frac{B}{D_{i j}{ }^{\beta}}\right), D_{i j} \geq D_{c} \\
-\varepsilon D_{i j}, D_{i j}<D_{c}
\end{array}\right. \\
& \mathbf{F}_{i j}=-\partial U_{i j} / \partial \mathbf{r}_{i j}
\end{aligned}
$$

Here, $D_{i j}=r_{i j} / r_{C N T}-2$ is the dimensionless distance between CNT surfaces, $r_{i j}$ is intercenter distance between interacting particles (here and below we use bold font for vectors and regular font for their absolute values). For the small and negative distances, corresponding to intersection and touching of CNTs, generalized Lennard-Jones potential is replaced with a linear potential exerting constant repulsive force. In our simulations, for the normalized distances $D>6$, vdW interactions are neglected.

Table 1 gives parameterization of isotropic $\mathrm{vdW}$ potential (1) used in this work.

Table 1. Parameters of isotropic van der Waals potential.

\begin{tabular}{|c|c|c|c|c|c|}
\hline$A$ & $B$ & $\alpha$ & $\beta$ & $\varepsilon, \mathrm{meV}$ & $D_{c}$ \\
\hline 0.0223 & 1.31 & 9.5 & 4 & 71.24 & 0.4 \\
\hline
\end{tabular}

In the previous implementation of MDEM, the coarse-grained covalent interactions within a CNT were represented with the parallel bond model [13, 21]. Parallel bonds specify linear relations between relative stretching, shearing, twisting and bending of CNT segments, and the corresponding tension and shear forces, as well as torsional and bending moments. These relations were specified in a decoupled incremental form, and the corresponding stiffnesses were derived from Euler-Bernoulli beam theory [13]. However, this approach performs poorly when it is necessary to study large strains of CNTs, since it is unable to capture the coupling between bending and twisting terms. This leads to significant nonconservation of energy and necessity of using artificial local damping, needed to stabilize numerical time integration. On the other hand, it is hard to generalize parallel bond for the case of nonlinear constitutive behavior, occurring at large deformations of CNT. In order to bypass these limitations, in the new implementation we have replaced parallel bonds with more general and stable enhanced vector model (EVM) of an elastic bond developed recently $[19,20]$.
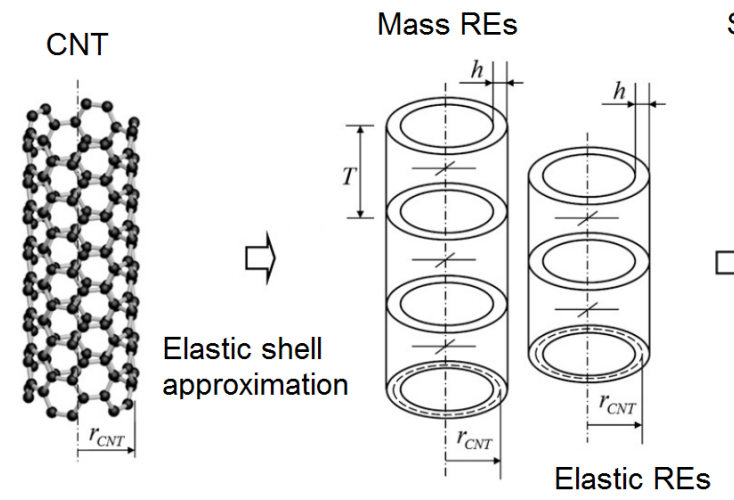

Spherical particles

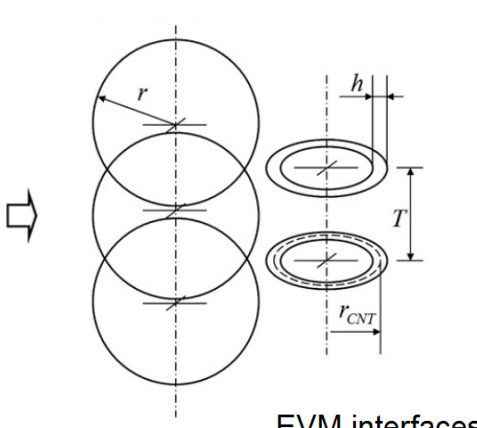

Fig. 1. Illustration of the coarse-graining concept used in MDEM. 
The EVM is based on a binding potential, describing the behavior of an elastic bond linking two rigid bodies. The formulation provides straightforward generalization on the case of large strains and accounts for a bending-twisting coupling. Consider two equal-sized spherical particles $i$ and $j$ with equilibrium separation $a$ and equilibrium orientation described in terms of orthogonal vectors $\mathbf{n}_{i k}, \mathbf{n}_{j k}$, as depicted in Fig. 2a $\left(\mathbf{n}_{i 1}=-\mathbf{n}_{j 1}, \mathbf{n}_{i k}=\mathbf{n}_{j k}, k=2,3\right)$. Then EVM bond potential is given as follows:

$$
\begin{aligned}
U & =\frac{B_{1}}{2}\left(r_{i j}-a\right)^{2}+\frac{B_{2}}{2}\left(\mathbf{n}_{j 1}-\mathbf{n}_{i 1}\right) \cdot \mathbf{d}_{i j}+ \\
& +B_{3} \mathbf{n}_{i 1} \cdot \mathbf{n}_{j 1}-\frac{B_{4}}{2}\left(\mathbf{n}_{i 2} \cdot \mathbf{n}_{j 2}+\mathbf{n}_{i 3} \cdot \mathbf{n}_{j 3}\right)
\end{aligned}
$$

Here $\mathbf{r}_{i j}$ is the radius vector connecting centers of bonded particles, $\mathbf{d}_{i j}=\mathbf{r}_{i j} / r_{i j}$. Expressions for corresponding forces and torques acting between bonded particles $i$ and $j$ have the forms:

$$
\begin{aligned}
& \mathbf{F}_{i j}=B_{1}\left(r_{i j}-a\right) \mathbf{d}_{i j}+\frac{B_{2}}{2 D_{i j}}\left[\left(\mathbf{n}_{j 1}-\mathbf{n}_{i 1}\right)-\left(\left(\mathbf{n}_{j 1}-\mathbf{n}_{i 1}\right) \cdot \mathbf{d}_{i j}\right) \mathbf{d}_{i j}\right], \\
& \mathbf{M}_{i j}=-\frac{B_{2}}{2} \mathbf{d}_{i j} \times \mathbf{n}_{i 1}+\mathbf{M}^{T B}, \\
& \mathbf{M}_{j i}=\frac{B_{2}}{2} \mathbf{d}_{i j} \times \mathbf{n}_{j 1}-\mathbf{M}^{T B}, \\
& \mathbf{M}^{T B}=B_{3} \mathbf{n}_{j 1} \times \mathbf{n}_{i 1}-\frac{B_{4}}{2}\left(\mathbf{n}_{j 2} \times \mathbf{n}_{i 2}+\mathbf{n}_{j 3} \times \mathbf{n}_{i 3}\right) .
\end{aligned}
$$

Parameters $B_{1}, B_{2}, B_{3}, B_{4}$ are directly related to longitudinal, shear, bending, and torsional rigidities of a bond, respectively. Note that in the framework of the EVM, these stiffnesses are independent. Therefore, any values of stiffnesses can be fitted. In the simplest case, parameters $B_{1}, B_{2}, B_{3}, B_{4}$ can be calibrated using Euler-Bernoulli beam theory as follows (see papers $[19,20]$ for more details):

$$
B_{1}=\frac{E S}{a}, B_{2}=\frac{12 E J}{a}, B_{3}=-\frac{2 E J}{a}-\frac{G J_{p}}{2 a}, B_{4}=\frac{G J_{p}}{a},
$$

where $S, J, J_{p}$ are area, moment of inertia and polar moment of inertia of a hollow beam:

$$
S=2 \pi h r_{C N T}, J=\pi h r_{C N T}\left(r_{C N T}^{2}+h^{2} / 4\right), J_{p}=2 J \text {. }
$$

Microscopically computed Young's modulus $E=1029 \mathrm{GPa}$ and shear modulus $G=459 \mathrm{GPa}$ [7] are used. Table 2 gives the parameters of mass and elastic properties of the REs.
Table 2. Parameters of mass and elastic REs.

\begin{tabular}{|c|c|c|c|c|}
\hline$m, \mathrm{amu}$ & $I, \mathrm{amu} \times \AA^{2}$ & $S, \AA^{2}$ & $J, \AA^{4}$ & $J_{p}, \AA^{4}$ \\
\hline 2649 & $1.218 \times 10^{5}$ & 142.7 & 3.480 & 6.960 \\
\hline
\end{tabular}

The simulations are based on the rigid particle dynamics module of the waLBerla multiphysics framework, which is freely available under GPLv3 license at (www.walberla.net). A full description of the parallel algorithms and their realization $[18,22-25]$ is beyond the scope of this paper; here we only outline the basic features of our parallel simulation environment. The contact detection used for rigid body dynamics is slightly adapted for potentialbased interactions. This can be done by reinterpreting the actual shape of a particle as its cut-off distance for all potential based interactions. The actual contact detection is a two-step process. The first step is a broad phase collision detection which uses hierarchical hash grids [26, 27]. The second step uses algebraic formulas for narrow phase collision detection. Such a choice leaves space for possible algorithm generalizations allowing to incorporate rigid bodies of various sizes, e.g. for modeling systems of CNTs and nanoparticles [28]. The parallelization is based on standard Message Passing Interface (MPI) [29] for distributed memory architectures. The simulation domain is divided in a balanced manner into rectangular subdomains. These subdomains are distributed among the available processes such that every process is responsible for one or more subdomains. Each process stores the information of all rigid bodies that are within its associated subdomains. For correct contact detection of particles near the borders of a subdomain so-called ghost particles are introduced. These ghost particles mirror particles which touch the subdomain but are located at a different one. This way they are available for contact detection and force calculation. Time integration can then take into account forces exerted by local contacts, but also forces exerted by the contacts with ghost particles. The general scalability of this approach is proven up to almost half a million cores [18]. However, in our case some serial operations (e.g. gathering of the total potential and kinetic energy of the system) limit the efficiency of the parallelization.

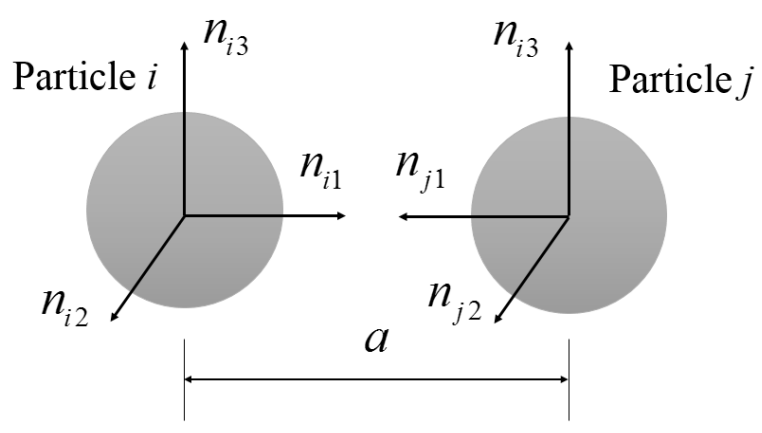

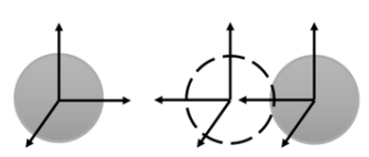

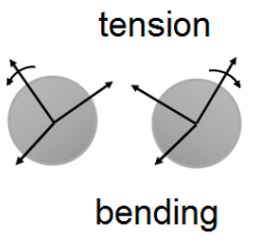

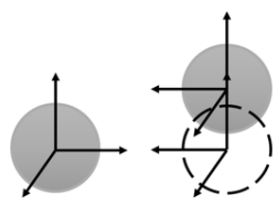

shear

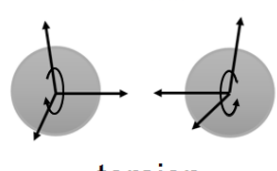

torsion

Fig. 2. Schematics of two rigid particles linked with EVM bond (a). Four modes of the bond deformation (b). 


\section{Numerical results}

The problem of self-assembly and mechanics of a representatively large specimen of a CNT film or a buckypaper is still an open question. In this work, we approach the problem of self-assembly of CNT films and buckypapers as a benchmark for validation of our approach and demonstration of its scalability.

\subsection{Ultra-thin CNT film}

Numerical simulation of a CNT film self-assembly is set up as follows. A number of initially straight CNTs of given length and orientation are deposited in a $3 \mathrm{D}$ rectangular box, with periodic boundary conditions imposed along in-plane $(x$ and $y$ ) directions (Fig. 3a). The model contains 400 CNTs with aspect ratio of 100 and length of $136 \mathrm{~nm}$ each (this corresponds to $2.4 \times 10^{5}$ model DOF and $1.6 \times 10^{6}$ coarse-grained vdW contacts). The orientation of CNT is set in such a way that in-plane distribution of CNT orientations is uniform, but out-of-plane component is set in a relatively narrow range of $0.1 \mathrm{rad}$. This system of CNTs is relaxed during 20000 cycles $(0.4 \mathrm{~ns})$ in a damped dynamic simulation. At the initial stage, CNTs repel, excluding geometric intersections due to repulsive part of the potential (1). At the next stage of relaxation, CNTs evolve into a flat entangled network of CNT bundles (Fig. 3b). An equilibrated metastable configuration is characterized by certain amount of elastic strain energy "locked" by vdW adhesion of CNTs. Fig. 3c illustrates the evolution of kinetic energy, elastic strain energy and vdW adhesion energy during the spontaneous self-assembly process.

This relatively simple numerical experiment is used in our work to probe the scalability and achievable model sizes. Table 3 illustrates the parallel scalability observable in our numerical experiments. It is clear that our platform demonstrates nearly linear the distributed memory scalability up to hundreds of computational cores. Previous large-scale tests of waLBerla [18] indicated that our framework is likely scalable up to hundreds thousands of cores and could be efficiently run on largest world supercomputers from TOP500 list.

\subsection{CNT buckypaper}

It appears that the new platform will allow us to approach carbon nanotube systems that are orders of magnitude larger than those studied in most of the previous works. As shown in Fig. 4, we successfully managed to simulate the relaxation of one cubic micrometer of a thick CNT film (buckypaper) with reasonable density of 0.013 $\mathrm{g} / \mathrm{cm}^{3}$. The model contained $1.8 \times 10^{7}$ rigid body DOF and approximately $1.1 \times 10^{8}$ coarse-grained vdW contacts between rigid segments. Simulation setup followed the procedure described above, but, unlike the case of a thin film, periodic boundary conditions were applied along all three Cartesian axes. Simulation employed 156 CPU cores of a computational cluster, and took 5.5 hours. A complete relaxation took $10^{5}$ timesteps ( $2 \mathrm{~ns}$ ).
Table 3. Parallel scalability of CNT film self-assembly simulations.

\begin{tabular}{|c|c|c|c|c|}
\hline$N$ of cores & $\begin{array}{l}\text { Number of } \\
\text { nodes }\end{array}$ & $\begin{array}{c}\text { Number of } \\
\text { MPI processes }\end{array}$ & DOF & Time, $s$ \\
\hline 1 & 1 & 1 & \multirow{8}{*}{$2.4 \times 10^{5}$} & 6755 \\
\hline 2 & 1 & 2 & & 3608 \\
\hline 4 & 1 & 4 & & 1971 \\
\hline 8 & 1 & 8 & & 973 \\
\hline 16 & 1 & 16 & & 499 \\
\hline 32 & 2 & 32 & & 255 \\
\hline 64 & 4 & 64 & & 144 \\
\hline 128 & 8 & 128 & & 86 \\
\hline
\end{tabular}

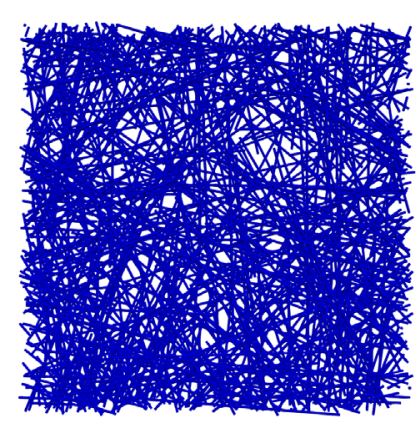

a

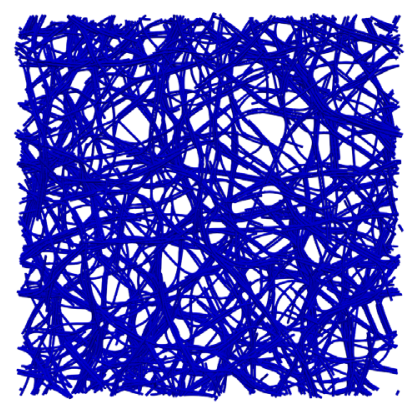

b

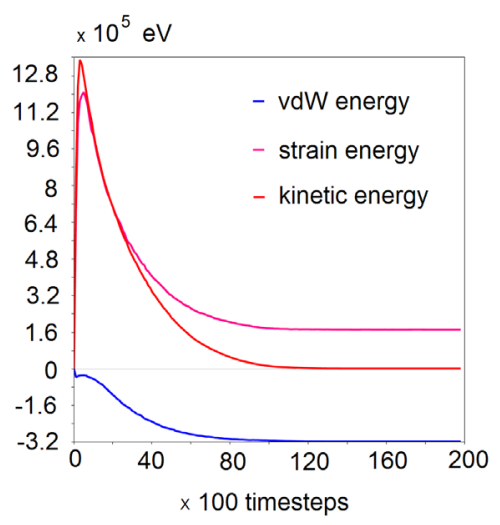

$\mathrm{c}$

Fig. 3. Self-assembly of a carbon nanotube film. Appearance of a specimen consisting of $400 \mathrm{CNTs}$ with aspect ratio of 100 each at the initial (a) and final (b) moment of simulation. On the inset enlarged structure of the specimen. Evolution of system kinetic energy, vdW adhesion energy, elastic strain energy in the course of simulation (c)

\section{Conclusions}

In the present work, we have presented the new capabilities of mesoscopic distinct element method for modeling carbon nanotube systems. The method was re-implemented within highly scalable waLBerla multiphysics framework. Parallel bonds, employed in the previous implementation, were replaced with energy-conserving Enhanced Vector Model, which allowed stabilizing large-scale simulations of interacting elastic filaments. The engine incorporates energy-conserving integration of rigid body dynamics of arbitrary-shaped particles, and can be extended with the advanced potentials for van der Waals interactions $[13,30]$ and more realistic models for energy transfer to implicit 


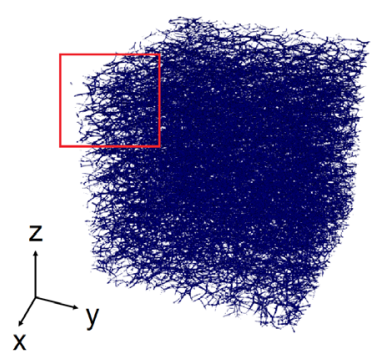

a

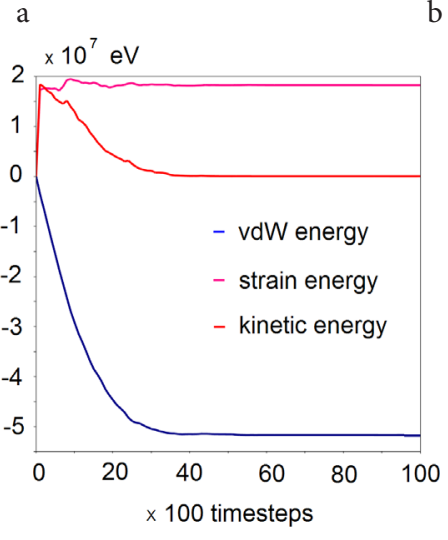

C
Fig. 4. $1 \mu \mathrm{m}^{3}$ specimen of a CNT buckypaper, containing $3 \times 10^{4}$ CNTs with aspect ratio of 100 each (a). Magnified microstructure of a material, featuring a network of bundles (b). Time evolution of potential and kinetic energy of the system (c).

degrees of freedom. Owing to the excellent scalability of simulations, the physical fidelity of modeling and the greatpotential for further extension, the MDEM framework could be established as a state of the art tool for numerical modeling of carbon nanotube materials.

Acknowledgments. I.A. Ostanin acknowledges the financial support from the Russian Science Foundation (RSF) under grant 17-73-10442 (the development of the system of CNT modeling based on waLBerla software). T. Dumitrica acknowledges support from NASA's Space Technology Research Grant NNX16AE03G. V.A. Kuzkin acknowledges financial support from the Russian Science Foundation under grant № 17-71-10213. High-performance computations presented in the paper were carried out on Skoltech Pardus HPC cluster http://crei.skoltech.ru/cdise/hpc/the-skoltech-hpc-clusterpardus-by-ibm-lenovo/.

\section{References}

1. S. Iijima. Nature 354, 56 (1991). DOI: 10.1038/354056a0

2. R.H. Baughman. Science. 297, $787 \quad$ (2002). DOI: 10.1126/science.1060928

3. M.S. Dresselhaus, G. Dresselhaus, P. Avouris. (eds.) Carbon nanotubes: synthesis, structure, properties, and applications. Springer, Berlin-New York (2001).

4. R. Saito, G. Dresselhaus, M.S. Dresselhaus. Physical properties of carbon nanotubes. World Scientific, Singapore (1998).

5. B. Yakobson, C, Brabec, J. Bernholc. Phys. Rev. Lett.
76(14), 2511 (1996). DOI: 10.1103/physrevlett.76.2511

6. T. Dumitrica, M. Hua, B. Yakobson. Proc. Natl. Acad.Sci. U.S.A. 103(16), 6105 (2006). DOI: $10.1073 /$ pnas.0600945103

7. D.-B. Zhang, T. Dumitrica. Appl. Phys. Lett. 93, 031919 (2008). DOI: 10.1063/1.2965465

8. I. Nikiforov, D.-B. Zhang, R. James, T. Dumitrica. Appl. Phys. Lett. 96, 123107 (2010). DOI:10.1063/1.3368703

9. M. J. Buehler. Journ. Mat. Res. 21(11), 2855 (2006). DOI: $10.1557 /$ jmr.2006.0347

10. S. W. Cranford, M. J. Buehler. Nanotechnology. 21, 265706 (2010). DOI: 10.1088/0957-4484/21/26/265706

11. R. Mirzaeifar, Z. Qin, M. Buehler. Nanoscale. 7(12), 5435 (2015). DOI: 10.1039/C4NR06669C

12. T. Anderson, E. Akatyeva, I. Nikiforov, D. Potyondy, R. Ballarini, T. Dumitrica. Journ. Nanotech. Eng. Med. 1(4), 0410009 (2010). DOI: 10.1115/1.4002609

13. I. Ostanin, R. Ballarini, D. Potyondy, T. Dumitrica. Journ. Mech. Phys. Sol. 61(3), 762 (2013). DOI: 10.1016/j.jmps.2012.10.016

14. I. Ostanin, R. Ballarini, T. Dumitrica. Journ. Appl. Mech. 81(6), 061004 (2014). DOI: 10.1115/1.4026484

15. I. Ostanin, R. Ballarini, T. Dumitrica. Journ. Mat. Res. 30(1), 19 (2015). DOI: 10.1557/jmr.2014.279

16. Y. Wang, I. Ostanin, C. Gaidau, T. Dumitrica. Langmuir. 31(45), 12323 (2015). DOI: 10.1021/acs.langmuir.5b03208

17. Itasca Consulting Group Inc., 2015. PFC3D (Particle Flow Code in Three Dimensions). Version 5.0. Itasca Consulting Group Inc., Minneapolis.

18. T. Preclik, U. Ruede. Comp. Part. Mech. 2, 173 (2015). DOI: $10.1007 / \mathrm{s} 40571-015-0047-6$

19. V.A. Kuzkin, I.E. Asonov. Phys. Rev. E. 86(5), 051301 (2012). DOI: 10.1103/PhysRevE.86.051301

20. V. A. Kuzkin, A. M. Krivtsov. Letters on materials. 7(4), 455 (2017). DOI: 10.22226/2410-3535-2017-4-455-458

21. D. Potyondy, P. Cundall. Int. J. Rock Mech. \& Min. Sci. 41(8), 1329 (2004). DOI: 10.1016/j.ijrmms.2004.09.011

22. K. Iglberger, U. Ruede. Comp. Sci.-Res. Dev. 25(1-2), 105 (2010). DOI: 10.1007/s00450-010-0114-4

23. D. Bartuschat, U. Ruede. Journ. Comp. Sci. 8, 1 (2015). DOI: $10.1016 /$ j.jocs.2015.02.006

24. C. Feichtinger, S. Donath, H. Köstler, J. Götz, U. Ruede. Journ. Comp. Sci. 2(2), 105 (2011). DOI: 10.1016/j.jocs.2011.01.004

25. J. Götz, K. Iglberger, C. Feichtinger, S. Donath, U. Ruede. Par. Comp. 36(2-3), 142 (2010). DOI: $10.1016 /$ j.parco.2010.01.005

26. C. Ericson. Real-time collision detection. CRC Press (2004).

27. K. Erleben, J. Sporring, K. Henriksen, K. Dohlman. Physics-based animation (graphics series). Charles River Media (2005).

28. Y. Wang, G. Drozdov, E. Hobbie, T. Dumitrica. ACS Appl.Mat. Int. 9(15), 13611 (2017). DOI: 10.1021 /acsami.7b01434

29. M. P. Forum. MPI: A message-passing interface standard. Technical report, Knoxville, TN, USA (1994).

30. G. Drozdov, I. Ostanin, I. Oseledets. J. Comp. Phys. 343, 110 (2017). DOI: 10.1016/j.jcp.2017.04.056 